\title{
SISTEMA DE CONTROLE E AQUISIÇÃO DE DADOS PARA MEDIDA DE REFLETÂNCIA UTILIZANDO MATLAB.
}

\author{
P. L. P. Morais $^{1,}{ }^{*}$; L. A. Berni ${ }^{2}$; N. Oliveira ${ }^{1}$; \\ 1 Faculdade de Tecnologia de São José dos Campos - Professor Jessen Vidal \\ Av. Cesare Mansueto Giulio Lattes, 1350 - Eugênio de Melo, São José dos Campos/SP, \\ CEP.: 12247-014, Brasil. \\ Telefone: (12) 3905-2423 \\ *zpedroluis@outlook.com \\ 2 Instituto Nacional de Pesquisas Espaciais \\ Av. dos Astronautas, 1.758 - Jardim da Granja, São José dos Campos/SP, \\ CEP.: 12227-010, Brasil. \\ Telefone: (12) 3208-6000
}

\begin{abstract}
RESUMO: As variações da irradiação solar total (TSI) influenciam o clima da Terra. Essas mudanças impactam no balanço de energia global e medições precisas são fundamentais para entender os efeitos em longo prazo dessa influência. Essas medições utilizam radiômetros de substituição elétrica, os quais dependem de cavidades absorvedoras de radiação solar. As cavidades possuem o interior revestido com materiais pretos para absorver a radiação solar incidente. Este trabalho consiste num projeto realizado no Laboratório Associado de Sensores e Materiais (LABAS) do Instituto Nacional de Pesquisa Espaciais (INPE), que visa desenvolver um sistema de controle e aquisição de dados em Matlab, para fazer leituras de refletância de objetos (incluindo as cavidades), expostos a uma luz emitida por um laser, com um sensor de fotodiodo acoplado a uma esfera integradora.
\end{abstract}

PALAVRAS-CHAVE: Sensor; Matlab; Aquisição de dados; Esfera integradora; Refletância; Laser.

\begin{abstract}
Variations in total solar irradiance (TSI) influence the Earth's climate. The global energy balance and climate can be impacted by changes in TSI, making accurate solar measurements important to discern the long-term effects influence. TSI measurements have been made continually by spaceborne instruments since 1978 . These measurements rely on active cavity radiometers, which use black interior surfaces to absorb incident sunlight. This coursework consists of a project carried out at the Laboratório Associado de Sensores e Materiais (LABAS) of the Instituto Nacional de Pesquisas Espaciais (INPE), which aims to develop a Matlab control and data acquisition system to make reflectance readings of objects (including cavities), exposed to a light emitted by a laser, with a photodiode sensor coupled to an integrating sphere.
\end{abstract}

KEYWORDS: Sensor; Matlab; Data acquisition; Integrative sphere; Reflectance; Laser.

\section{INTRODUÇÃO}

Este trabalho consiste num projeto realizado no Laboratório Associado de Sensores e Materiais (LABAS) do Instituto Nacional de Pesquisa Espaciais (INPE), que visa desenvolver um software de sistema de controle e aquisição de dados em Matlab, para fazer leituras de refletância de objetos, expostos a uma luz emitida por um laser, com um sensor de fotodiodo acoplado a uma esfera integradora. 
O trabalho proposto visa facilitar a medida de refletância de objetos e que seja de fácil utilização pelos pesquisadores da área de Sensores e Materiais.

\subsection{Aquisição de dados}

A Aquisição de Dados (DAQ) é o processo de medição de um fenômeno elétrico ou físico, como: tensão, corrente, temperatura, pressão, som, entre outros fenômenos com o uso de um computador. (NATIONAL INSTRUMENTS, 2019).

Um Sistema de Aquisição de Dados é formado por sensores, hardware de aquisição e medição de dados e um computador com software programável. Os sistemas DAQ baseados em PC exploram a capacidade de processamento, produtividade, sistemas de visualização e recursos de conectividades dos computadores padrão da indústria. Com isso, temos uma solução de medição poderosa e flexível. (Ibidem, 2019).

A medição de um fenômeno físico, como a temperatura de uma sala, intensidade de uma fonte luminosa ou força aplicada a um objeto, começa pelo sensor. Um sensor converte um fenômeno físico em um sinal elétrico mensurável. Dependendo do tipo de sensor, sua saída elétrica pode ser uma característica de tensão, corrente, resistência ou outro atributo elétrico que varie com o tempo. (Ibidem, 2019).

O hardware DAQ atua como a interface entre um computador e sinais do mundo exterior. Ele funciona basicamente como um dispositivo que digitaliza sinais analógicos de entrada de forma que um computador possa interpretá-los. Os três componentes principais de um dispositivo de aquisição de dados usados para medir um sinal são os circuitos eletrônicos de condicionamento de sinais, conversor analógico-digital e o barramento do computador. (Ibidem, 2019).

A Figura 1 tem-se um esquema geral de um sistema de aquisição.

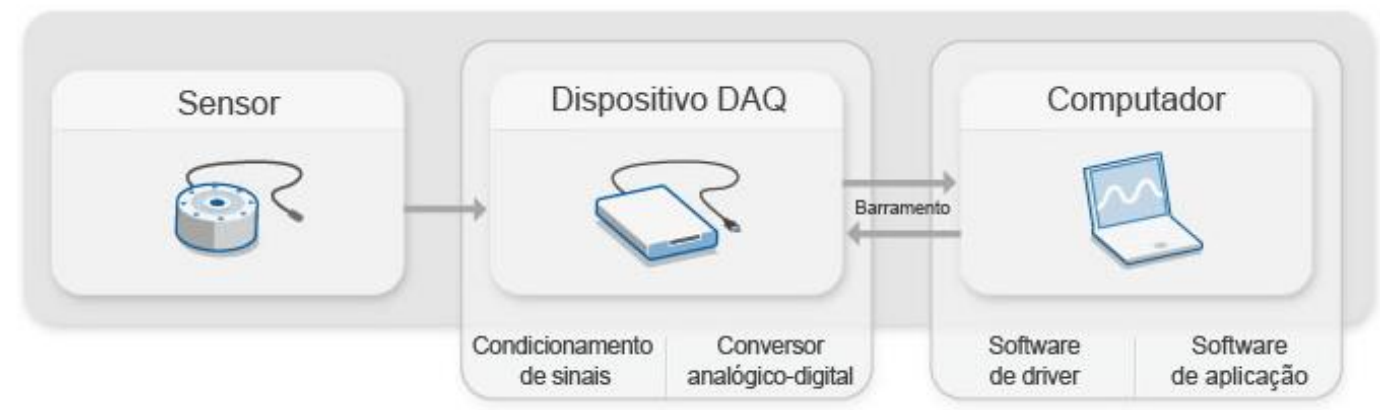

Figura 1. As partes de um sistema DAQ

\subsection{Objetivo geral}

O objetivo deste trabalho é desenvolver um sistema que possibilite medir a refletância de luz de cada ponto de um objeto, com o intuito de saber se o material está com uma refletância de luz adequada para absorver a radiação solar incidente.

\section{CONTEXTUALIZAÇÃO TECNOLÓGICA}

O sistema de refletância deste projeto consiste em: Um laser (Uniphase modelo 1125P) de $10 \mathrm{mV}$ de tensão e $632,8 \mathrm{~nm}$ de comprimento de onda, modulado espacialmente por um chopper que tem uma rotação ajustável por um controlador. Após modulado a luz atinge o objeto a ser medido, este objeto está instalado em uma esfera integradora. Um sensor acoplado 


\section{ISSN $2447-5378$}

na esfera é utilizado para captar luz refletida pelo objeto. Posteriormente os valores obtidos pelos sensores são enviados para um hardware de aquisição de dados logo depois mandado para o software no computador para tratamento desses dados.

A Figura 2 apresenta o sistema de refletância utilizado neste projeto.

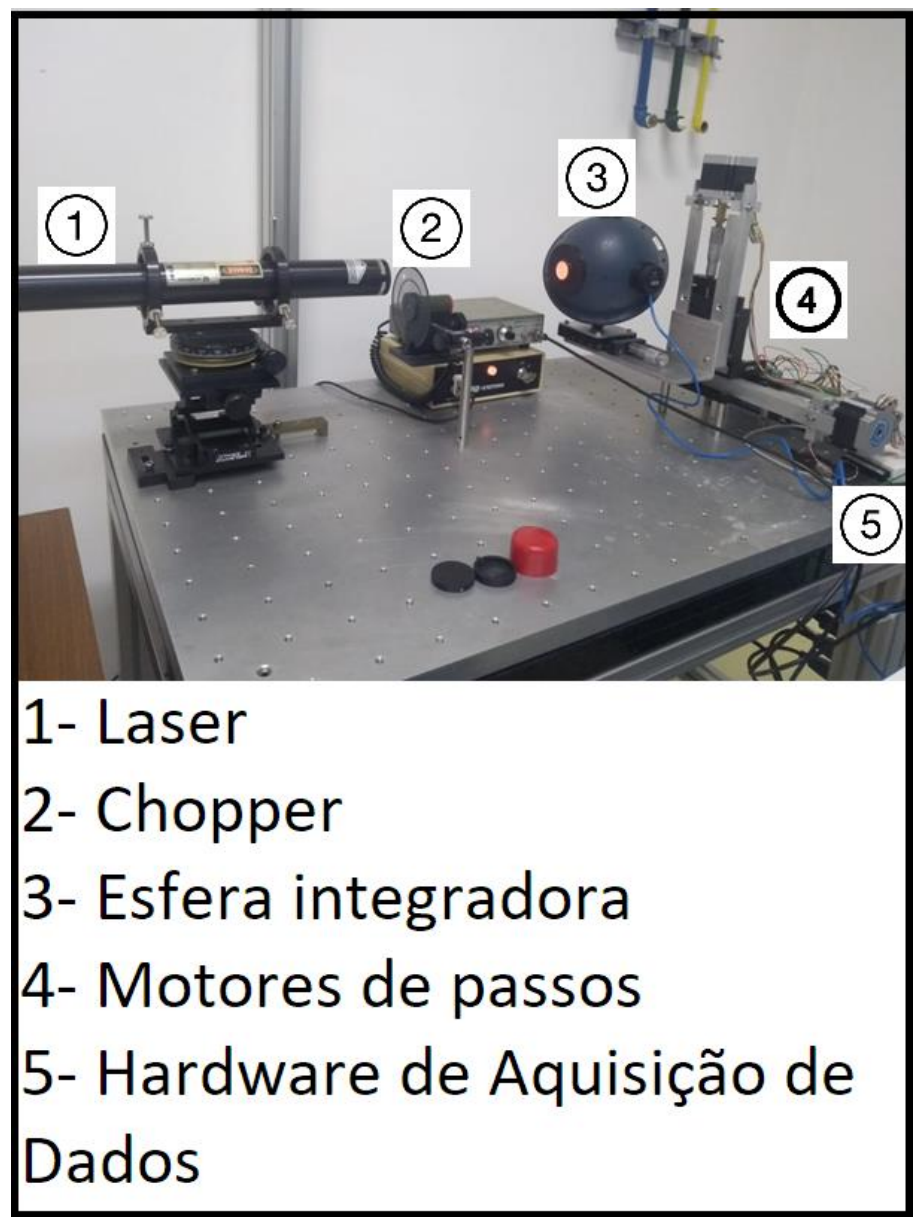

Figura 2. Sistema de refletância

\subsection{Medidas com a Esfera Integradora}

Transmitância representa a fração da energia luminosa que consegue atravessar uma determinada espessura de um material, sem ser absorvida. Ou seja, a capacidade de transmitir a luz. Posicionando uma amostra na entrada junto à fonte luminosa pode-se descobrir sua transmitância comparando as duas medidas de fluxo com e sem a amostra presente. Se a mesma amostra for posicionada em uma das outras aberturas no interior da esfera é possível medir a sua refletância, também por comparação (KASVI, 2018).

As duas configurações podem ser vistas na imagem da Figura 3. 
Medindo a transmitância

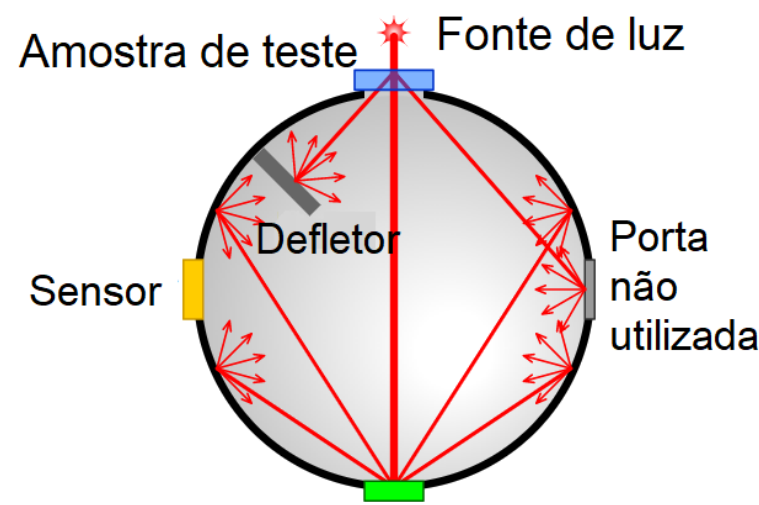

Refletância padrão
Medindo a refletância

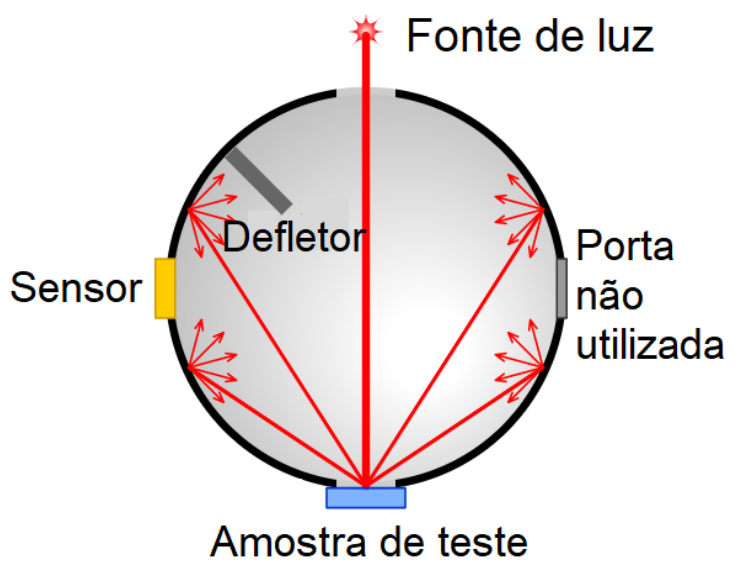

Figura 3. Aplicações da esfera integradora

\subsection{Tecnologias Utilizadas}

Nesta seção serão introduzidas as tecnologias utilizadas durante o desenvolvimento do projeto.

\subsubsection{Matlab}

Matlab é um sistema para cálculo científico desenvolvido pela MathWorks Inc. É um software pago, mas é disponível uma avaliação para testes durante 30 dias. É um software muito utilizado na área cientifica e na engenharia. O termo Matlab tem origem na conjugação dos termos Matrix e Laboratory. Ele proporciona um ambiente de fácil utilização com uma notação intuitiva, mas poderosa (MATHWORKS, 2019).

\subsubsection{PsychToolBox}

Psychophysics Toolbox Version 3 (PTB-3) é um conjunto gratuito de funções Matlab e GNU Octave para pesquisa em visão e neurociência. Torna mais fácil sintetizar e mostrar estímulos visuais e auditivos controlados com precisão e interagir com o observador (PSYCHTOOLBOX.ORG, 2019).

O Psychtoolbox foi utilizado neste projeto para mapear as teclas do teclado e ser possível o controle dos motores de passos manualmente para os ajustes iniciais.

\subsection{Tecnologias Existentes}

Com objetivo de demonstrar os fatores que influenciaram na decisão do desenvolvimento, foram coletados informações e conceitos sobre métodos ou equipamentos alternativos para a medição de espectro.

$\mathrm{Na}$ Tabela 1, tem-se uma comparativa das soluções existentes. 
Tabela 1. Comparativo das principais características

\begin{tabular}{cccc}
\hline Características & Espectrofotômetro & $\begin{array}{c}\text { Sistema } \\
\text { Instituto } \\
\text { PMOD }\end{array}$ & $\begin{array}{c}\text { Sistema } \\
\text { proposto pelo } \\
\text { autor }\end{array}$ \\
\hline $\begin{array}{c}\text { Leitura de } \\
\text { refletância por } \\
\text { pontos }\end{array}$ & - & $\mathrm{X}$ & $\mathrm{X}$ \\
$\begin{array}{c}\text { Média total da } \\
\text { refletância do } \\
\text { objeto }\end{array}$ & $\mathrm{X}$ & $\mathrm{X}$ & - \\
$\begin{array}{c}\text { Geração de } \\
\text { tabelas }\end{array}$ & - & $\mathrm{X}$ & $\mathrm{X}$ \\
$\begin{array}{c}\text { Geração de } \\
\text { gráficos em 2D }\end{array}$ & - & $\mathrm{X}$ & $\mathrm{X}$ \\
$\begin{array}{c}\text { Geração de } \\
\text { gráficos em 3D }\end{array}$ & - & - & $\mathrm{X}$ \\
\hline
\end{tabular}

\subsubsection{Espectrofotômetro}

O Espectrofotômetro é um aparelho amplamente utilizado em laboratórios, cuja função é a de medir e comparar a quantidade de luz (energia radiante) absorvida por uma determinada solução, transmitância de vidros e refletância utilizando módulo com esfera integradora. $\mathrm{Ou}$ seja, ele pode ser usado para medir (identificar e determinar) a concentração de substâncias, que absorvem energia radiante, em um solvente. Este aparelho possui uma gama de aplicações e está presente em várias áreas, tais como em química, física, bioquímica e biologia molecular. O grande inventor deste instrumento tão fundamental nos dias de hoje foi o químico americano Arnold O. Beckman, em 1940 (INFO ESCOLA, 2014).

Em geral, um espectrofotômetro possui uma fonte estável de energia radiante (normalmente uma lâmpada incandescente), um seletor de faixa espectral ( prismas ou redes de difração, que seleciona o comprimento de onda da luz que passa através da solução de teste), um recipiente (ou suporte) para colocar a amostra a ser analisada (a amostra deve estar em recipientes apropriados como as cubetas e tubos de ensaio) e, um detector de radiação, que permite uma medida relativa da intensidade da luz. A base da espectrofotometria, portanto é passar um feixe de luz através da amostra e fazer a medição da intensidade da luz que atinge o detector. O espectrofotômetro compara quantitativamente a fração de luz que passa através de uma solução de referência e uma amostra de teste (Ibidem, 2014).

Existem duas classes de espectrofotômetros: o de feixe simples e o de duplo feixe e eles são constituídos, essencialmente, por cinco componentes principais: as fontes de radiação, o monocromador, a porta amostras, os detectores e o indicador de sinal (NIST, 2019).

O resultado da espectrofotometria é dado por um gráfico que é conhecido como espectro e fornece informações de intensidade por comprimento de onda da fonte de luz. Essa faixa de comprimentos de onda desejados pode ser selecionada antes da realização das medidas, o que 


\section{ISSN $2447-5378$}

torna a medida mais específica e eficaz já que não será necessário um número excessivo de dados para obter o resultado esperado (NIST, 2019).

\subsubsection{Sistema Experimental do Instituto PMOD/WRC}

O sistema experimental, disponível no instituto PMOD/WRC na Suíça, permite medir a refletância em vários pontos da amostra para a construção de um mapa de refletância, bem como a determinação da refletância média. O sistema é formado por: um laser, um chopper, uma lente, e uma esfera integradora com um detector acoplado. O detector fotodiodo de silício é conectado a um amplificador lock-in. Todo o sistema está montado em um laboratório ótico onde as paredes, piso, teto e armários estão pintadas de preto para minimizar a interferência de outras fontes de radiação durante os experimentos (CARLESSO, 2019).

A decisão para o desenvolvimento deste trabalho foi tomada considerando a dificuldade de fazer medidas de ponto em ponto de objetos, levando em consideração que os espectrofotômetros geram apenas uma média de refletância geral do objeto, e para medir objetos no instituto PMOD/WRC demanda tempo, investimento, pessoas e depende da disponibilidade do instituto.

\section{PROCESSOS FÍSICOS E LÓGICOS DO SISTEMA}

Neste Capítulo apresenta-se, brevemente, o fluxo de execução do sistema e os códigos mais relevantes utilizados no desenvolvimento do presente trabalho.

\subsection{Fluxos de Execução do Sistema}

$\mathrm{Na}$ Figura 4 pode-se ver a arquitetura do sistema.

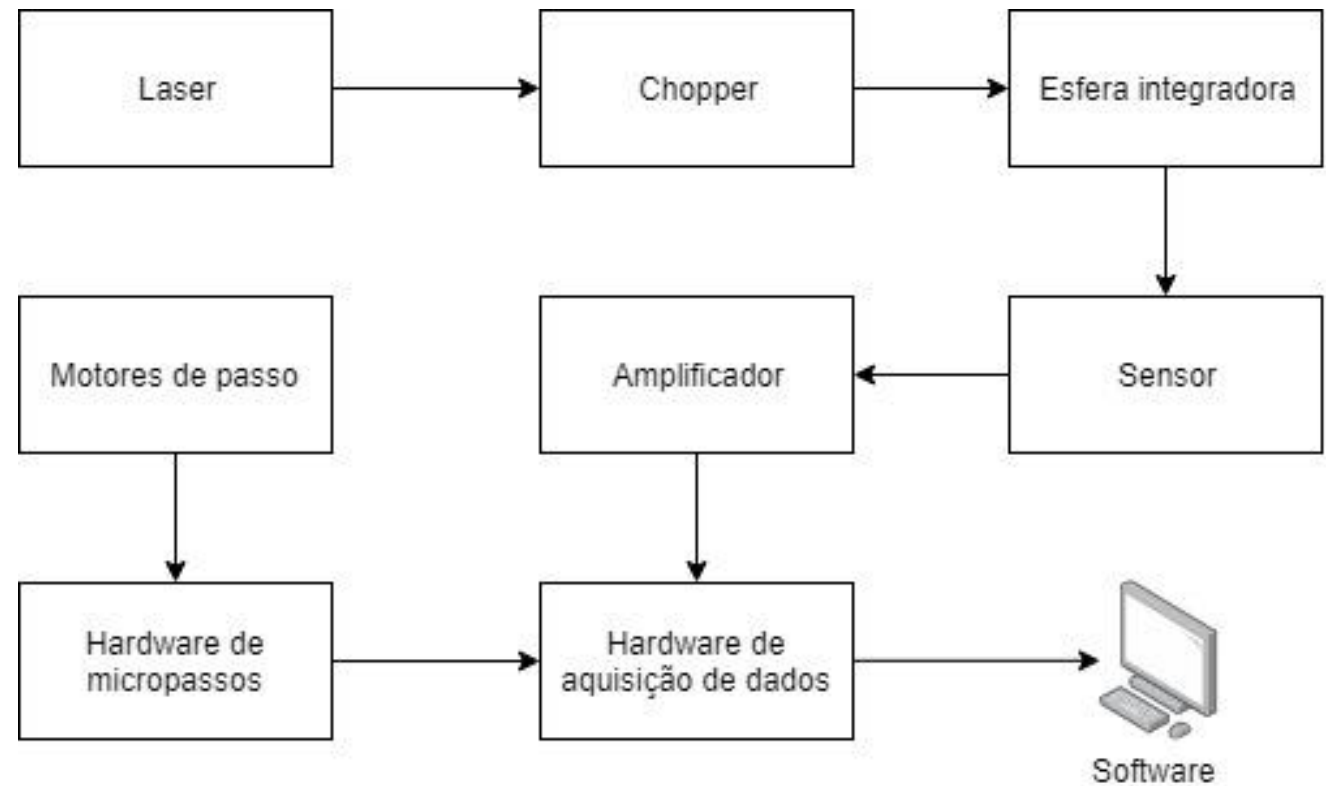

Figura 4. Arquitetura do sistema 
Na Figura 5 pode-se ver o fluxograma de execução do software, os processos envolvidos na interação do usuário com o software, as medidas geradas e os gráficos, de acordo com os ajustes estabelecidos pelo usuário.

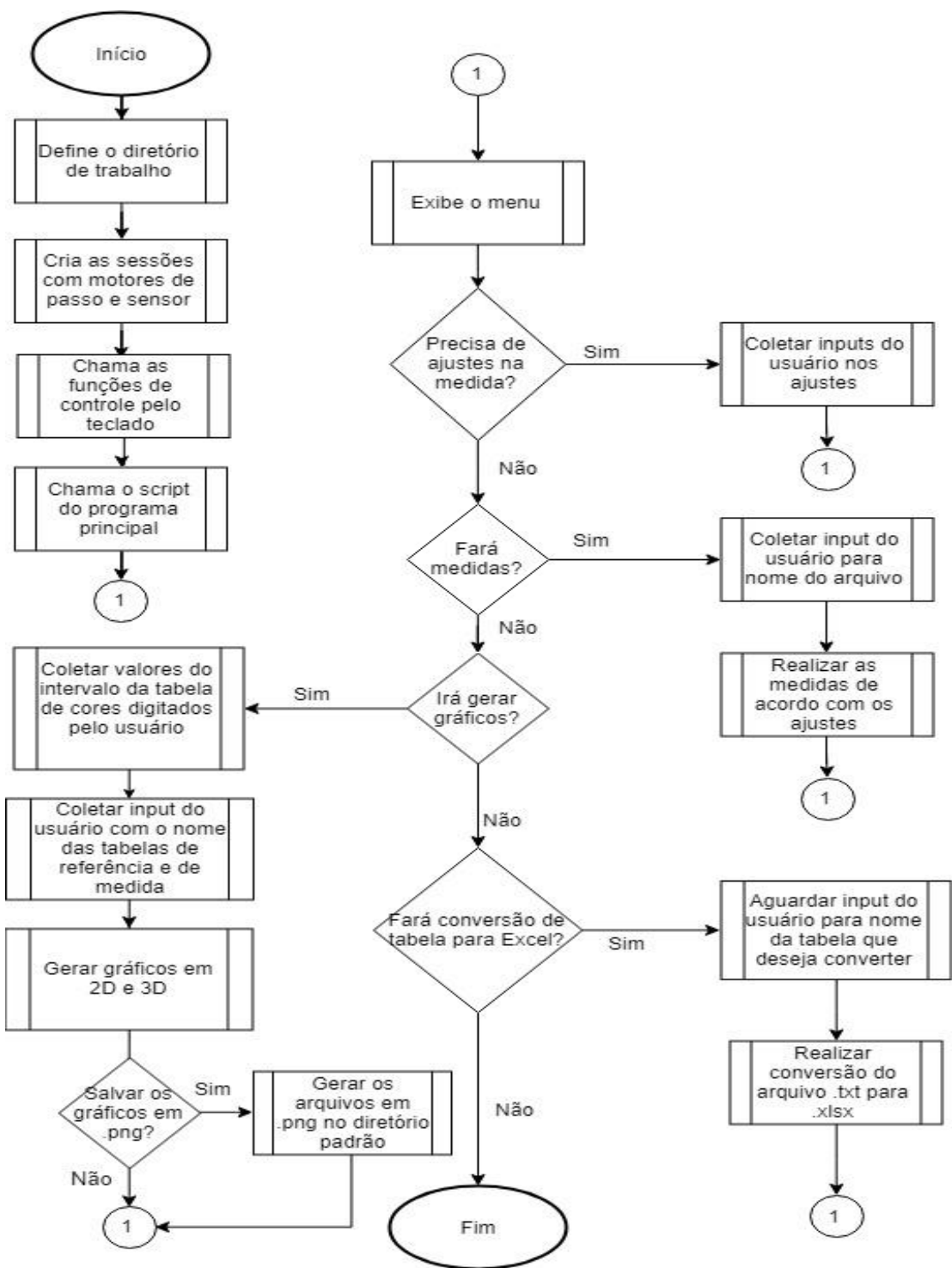

Figura 5. Fluxograma de execução do software

\subsection{Início e Fim das Medidas}

Após realizar os ajustes, a função principal do programa está pronta para ser iniciada. Assim que iniciada, o usuário deverá inserir um nome para o arquivo que contém as tabelas que será gerado e é onde será gravado e guardado os valores das medidas de cada ponto. Ao iniciar o programa, os motores devem ser deslocados para a posição inicial que é calculada da seguinte forma: $\mathrm{x}=$ - (área / 2) e y = - (área / 2). Exemplo: levando em consideração em que a área é 6 então fica: $\mathrm{x}=-(6 / 2)$ e $\mathrm{y}=-(6 / 2), \log \mathrm{x}=-3$ e $\mathrm{y}=-3$. Também é realizado o cálculo da quantidade de passos que será dado de acordo com o ponto inicial. Exemplo: ponto inicial = (área / 2) *400, logo ponto inicial $=(6 / 2) * 400=1200$. Ou seja, para chegar ao ponto $(-3,-$ $3)$ os motores precisarão dar 1200 passos em ambos os eixos. 
A Figura 6 apresenta um plano cartesiano demonstrativo, indicando o deslocamento de onde seria o centro do objeto a ser medido. Observa-se que os motores de passos estão programados para se mover um de cada vez.

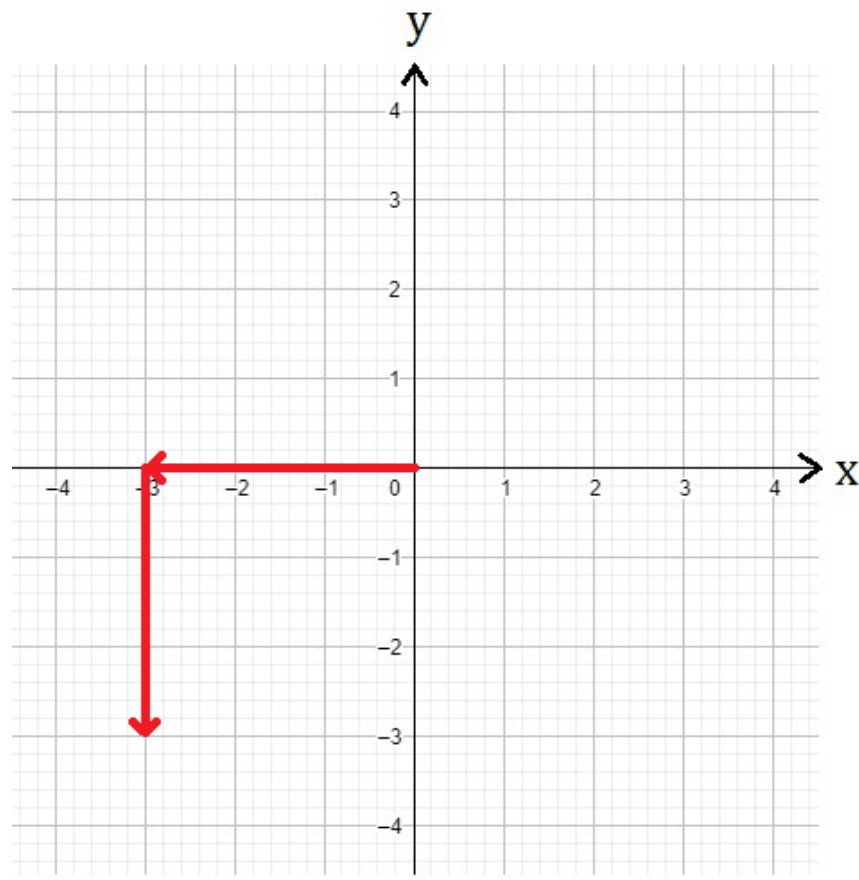

Figura 6. Deslocamento Inicial

Após a posição inicial ser definida o programa mapeia os passos de acordo com os valores da área e intervalo inseridos pelo usuário. Os motores fazem um caminho padrão nas medidas com a única diferença sendo o tamanho do quadrado, seu ponto inicial será sempre no $3^{\circ}$ quadrante do plano cartesiano.

A seguir a Figura 7 apresenta o caminho a ser percorrido do exemplo anterior, levando em consideração o intervalo das medidas sendo igual a $1 \mathrm{~mm}$.

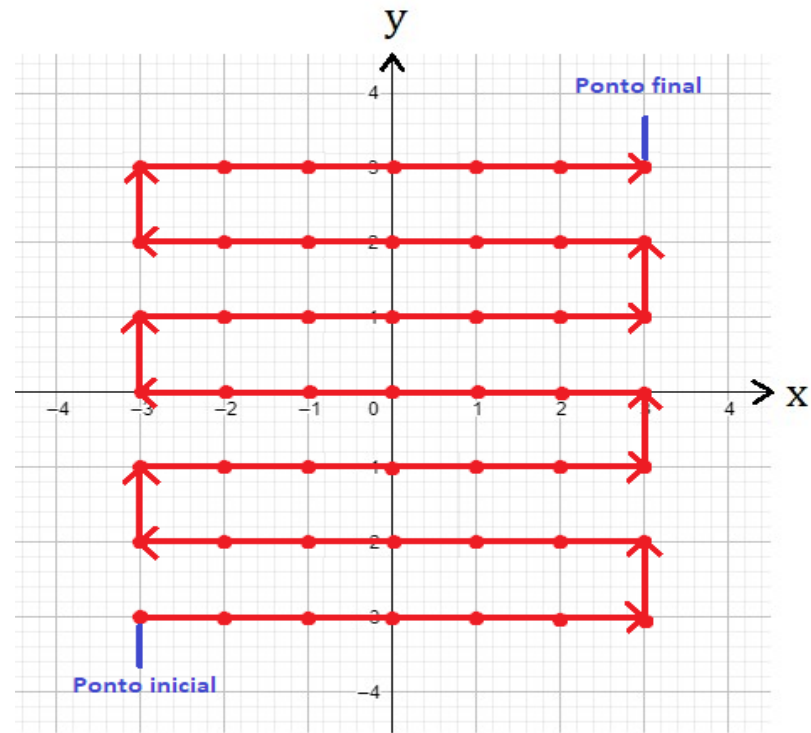

Figura 7. Caminho de Leitura 
O último ponto lido pode ser encontrado no $1^{\circ}$ ou $2^{\circ}$ quadrante. O programa faz uma verificação do valor da área, se o valor for um número par então o ponto final será no $1^{\circ}$ quadrante, se for um número ímpar o ponto final será no $2^{\circ}$ quadrante, assim ao final da medição os motores retornarão ao ponto $(0,0)$ de acordo com a verificação. Logo após as variáveis serão redefinidas para que uma nova medida possa ser feita e o programa retornará ao menu principal.

A Figura 8 apresenta o deslocamento das duas situações citadas onde a esfera retorna do ponto final ao ponto $(0,0)$.

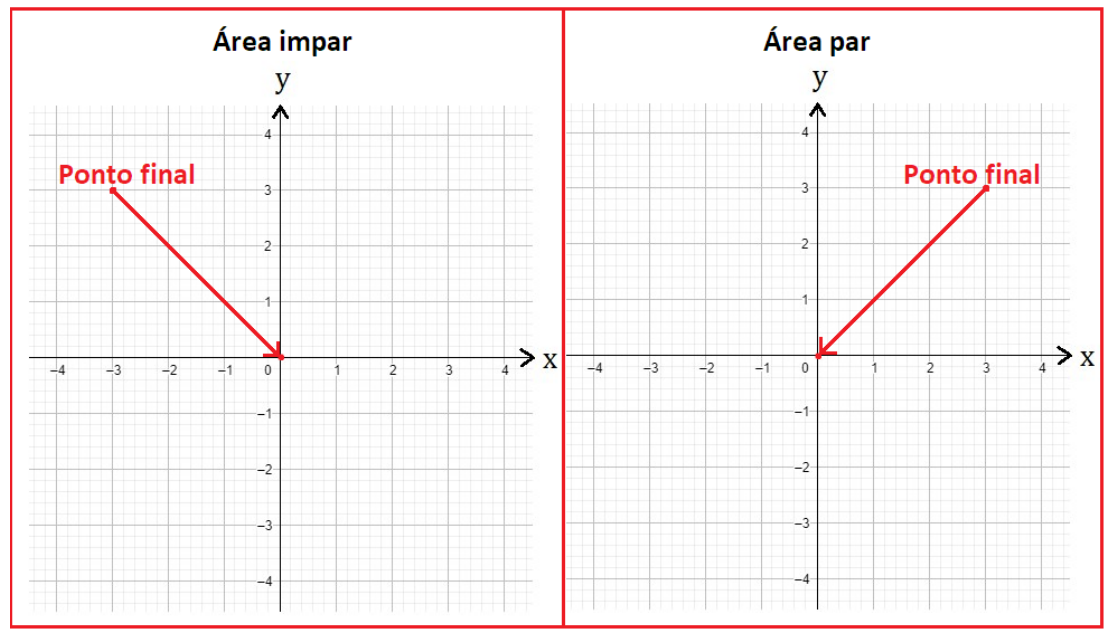

Figura 8. Deslocamento da esfera ao final da medição

\section{RESULTADOS E DISCUSSÃO}

Como resultado do desenvolvimento foi disponibilizado ao cliente um software de medição de refletância. O programa pode ser executado em qualquer computador que tenha $\mathrm{o}$ Matlab R2016b com o PsychToolBox instalado e todos os drivers necessários do NI DAQ6009.

A seguir seguem os resultados obtidos ao executar o programa.

\subsection{Controle de Motores de Passo}

O controle funciona conforme o esperado, tanto automaticamente quanto manualmente, para comandar o motor de passo para girar é preciso utilizar suas sessões criadas para realizar a interação entre o programa e os motores. Assim definindo uma quantidade de passos ou simplesmente apertando as setas direcionais para que ocorra o movimento. As sessões criadas para a interação entre programa x motor, tem 2 funções, a primeira para selecionar o sentido do giro (horário ou anti-horário), e a segunda para começar a girar de acordo com o sentido que foi ordenado. Esse processo é repetido uma ou mais vezes de acordo com a quantidade de passos que foi fornecido, para o controle automático são utilizados laços de repetições com o número de passos desejados, enquanto o controle manual aguarda o usuário pressionar a tecla que corresponde ao sentido que o motor irá girar.

\subsection{Medidas}

Os resultados a respeito do processo de medida foram verificados colocando o laser no lugar da esfera integradora mirando a luz diretamente na parede. Foi feito um plano cartesiano 


\section{ISSN $2447-5378$}

impresso para que a luz percorresse cada ponto dele. Analisando visualmente foi possível acompanhar cada erro e foi possível fazer alterações para chegar ao resultado esperado.

\subsection{Geração de Tabela}

As tabelas precisavam ser feitas de uma maneira que fosse possível ler via código para a geração dos gráficos e serem feitas de uma maneira que pudesse serem abertas no Microsoft Excel. Foi atendido todos os requisitos.

\subsection{Geração de Gráficos}

Os gráficos, conforme os requisitos, foram gerados dois gráficos, um em 2D e outro em 3D. Ambos são gráficos de cores utilizando a barra de cores sendo possível definir pelo usuário a escala da barra de cores.

A Figura 9 apresenta um teste feito com um desenho impresso em cartolina branca. As configurações são: Área $=12 \mathrm{~mm}^{2}$, Intervalo $=0,3 \mathrm{~mm}$ e escala utilizada de $65 \%$ a $100 \%$.

Percebe-se que nas áreas mais escuras do desenho, são mais claras no gráfico, isso é dada pela baixa refletância e o contrário acontece com as áreas mais claras e os pontos vão de -20 à +20 para ilustrar que são medidos 40 pontos no total.

\section{Gráfico 2D}

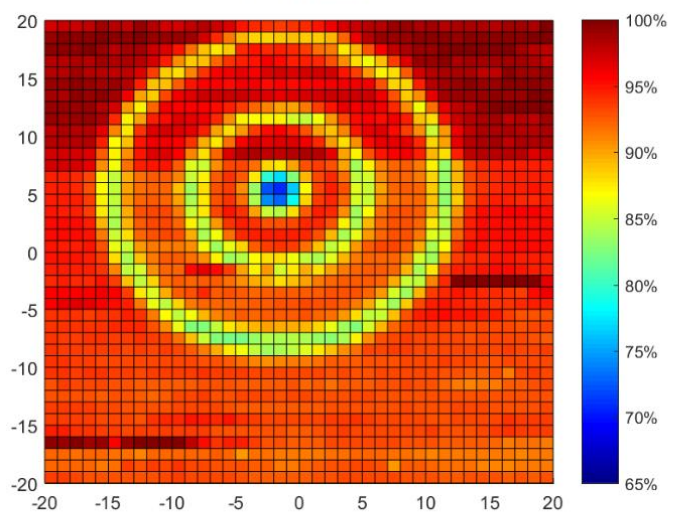

\section{Gráfico 3D}

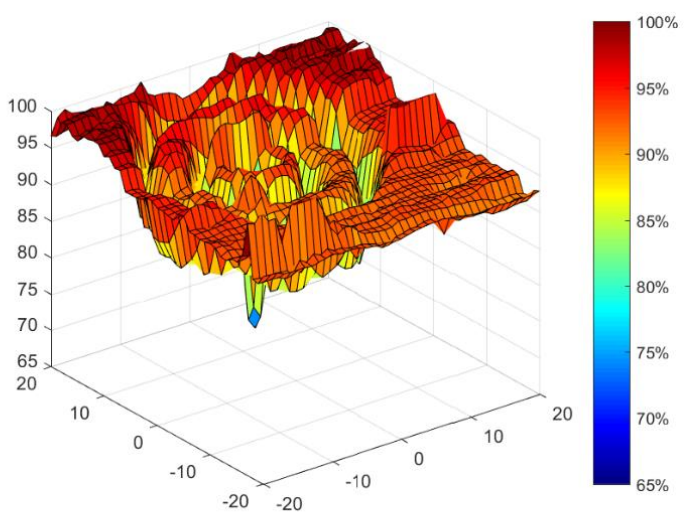

Objeto testado

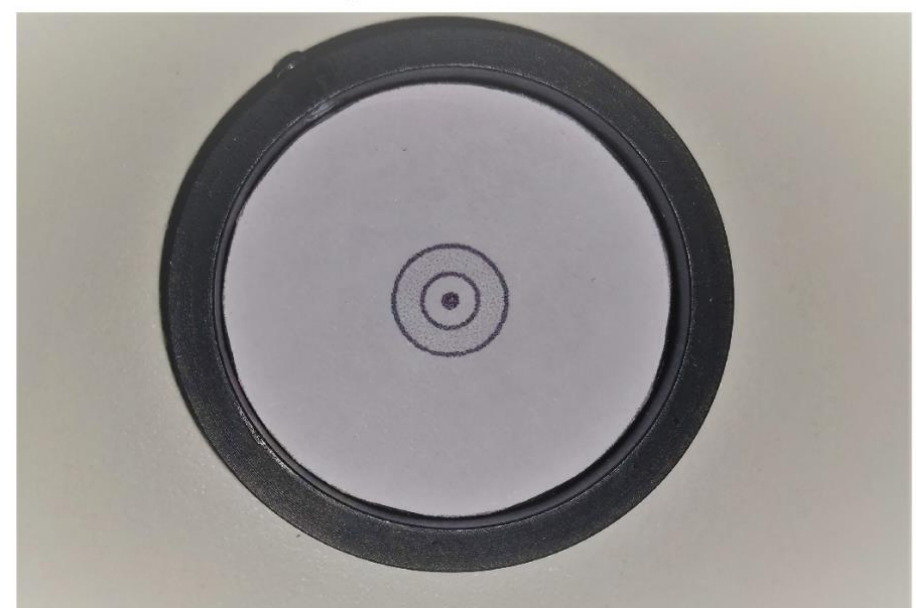

Figura 9. Exemplo de refletância 1 
A Figura 10 apresenta um outro exemplo com as mesmas características do exemplo anterior, porém com outro objeto testado e em diferentes escalas.

Gráfico 2D
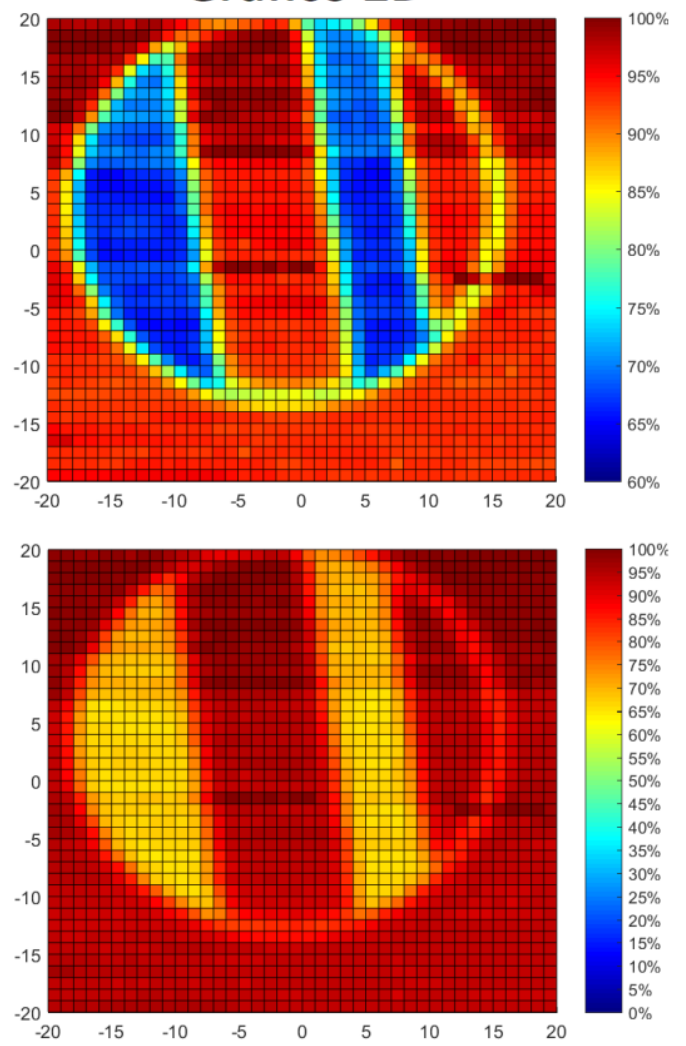

\section{Gráfico 3D}
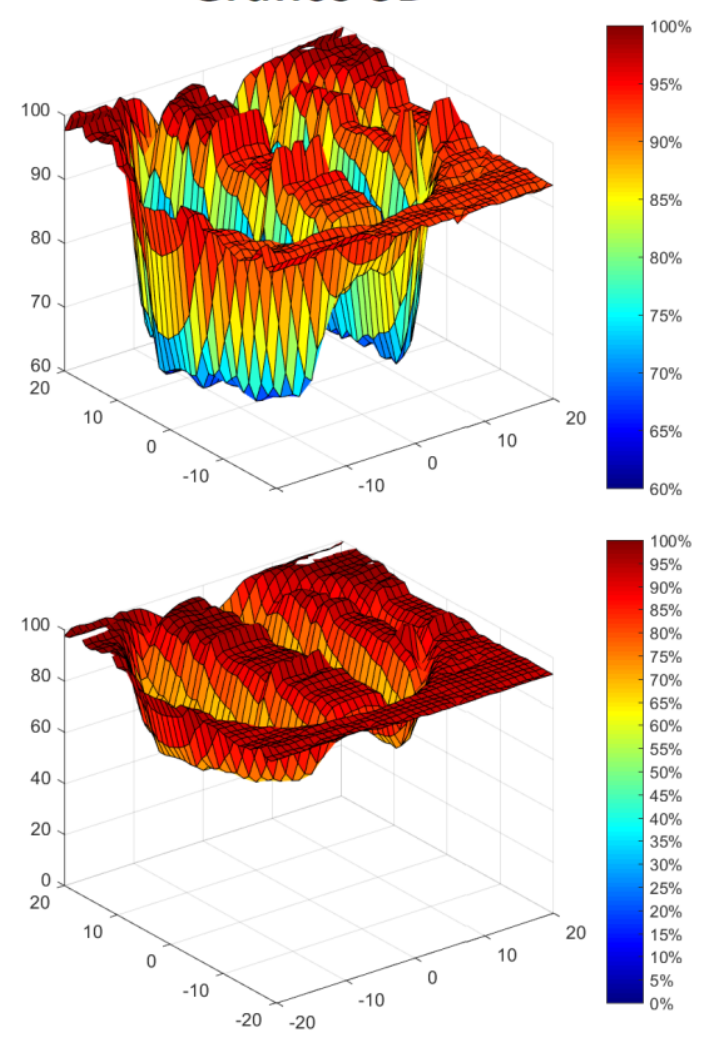

\section{Objeto testado}

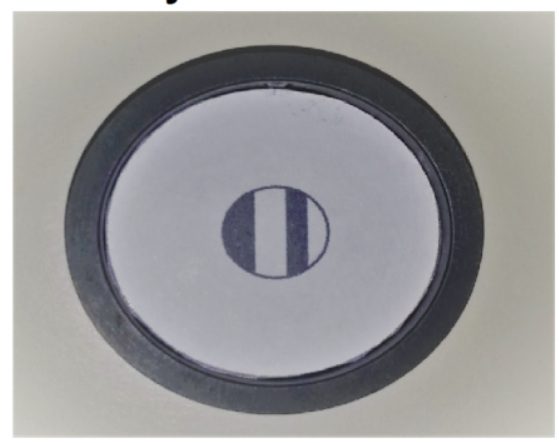

Figura 10. Exemplo de refletância 2

A Figura 11 apresenta um teste realizado com as seguintes configurações: Área = $10 \mathrm{~mm}^{2}$, intervalo $=0,25 \mathrm{~mm}$. Percebe-se que neste exemplo os pontos estão correspondendo exatamente a área que foi indicada nas configurações. 


\section{ISSN $2447-5378$}

interações do usuário. Os dados gerados nos testes demonstram integridade e os arquivos armazenados corretamente de acordo como foi exigido. As medidas geradas comparadas com as geradas foram fiéis, conforme constatado pelo pesquisador do projeto.

Como resultado do desenvolvimento foi disponibilizado ao cliente um software de medição de refletância. O programa pode ser executado em qualquer computador que tenha o Matlab R2016b com o PsychToolBox instalado e todos os drivers necessários do NI DAQ6009.

\section{REFERÊNCIAS BIBLIOGRÁFICAS}

BERTAN, H. H. Análise de aplicação e desempenho de uma esfera integradora em radiômetros para calibração de medidores de potência óptica. 2007. 130 f. Dissertação (Mestrado) - Curso de Engenharia Elétrica, Universidade Estadual de Campinas, Campinas, $2007 . \quad$ Disponível em: http://repositorio.unicamp.br/bitstream/REPOSIP/260064/1/Bertan_HiltonHenrique_M. pdf. Acesso em: 20/04/2019

BRAINARD, D. H. et al. PsychToolBox. 2019. Disponível em: http://psychtoolbox.org/. Acesso em: 10/06/2019.

CARLESSO, Franciele. Desenvolvimento de elemento sensor para medida de irradiância solar total. 2019. 225 f. Tese (Doutorado) - Curso de Pós-graduação em Engenharia e Tecnologia Espaciais/ciência e Tecnologia de Materiais e Sensores, Instituto Nacional de Pesquisas Espaciais, São José dos Campos, 2018. Cap. 5. Disponível em: http://mtcm21b.sid.inpe.br/col/sid.inpe.br/mtc-m21b/2018/02.04.23.10/doc/publicacao.pdf.

Acesso em: 07/06/2019.

KASVI. Espectrofotometria: Análise da concentração de soluções. (São José dos Pinhais). 2018. Disponível em: https://kasvi.com.br/espectrofotometria-analiseconcentracao-solucoes. Acesso em: 25/04/2019.

MATHWORKS. Math. Graphics. Programming. (Estados Unidos da América). 2019. Disponível em: https://www.mathworks.com/. Acesso em: 22/05/2019.

NATIONAL INSTRUMENTS. O que é aquisição de dados? Estados Unidos da América. 2019. Disponível em: http://www.ni.com/data-acquisition/what-is/pt. Acesso em: 09/04/2019.

VIEIRA, J. M. N. Matlab num Instante: Versão 1.4. 2004. Disponível em: http://sweet.ua.pt/jnvieira/MyDocs/MatlabNumInstante.pdf. Acesso em: 19/05/2019. 